\title{
SERUM CREATINE PHOSPHOKINASE ESTIMATIONS IN MYOCARDIAL INFARCTION
}

\author{
BY \\ F. G. WARBURTON, A. BERNSTEIN, AND ANN C. WRIGHT \\ From the Departments of Pathology and Medicine, Hope Hospital, Salford 6, Lancs.
}

Received January 15, 1965

Since the initial report on the clinical value of serum glutamic oxalacetic transaminase (SGOT) determinations in the diagnosis of myocardial infarction (LaDue, Wróblewski, and Karmen, 1954), a considerable amount of work has been done on the blood levels of other enzymes liberated from necrosed heart cells. Because of lack of specificity and difficulty of estimation, very few other enzyme estimations have been adopted as routine diagnostic tests. We have found the estimation of serum lactic dehydrogenase (SLD) to be a very useful supplementary test to SGOT determinations (Stewart and Warburton, 1961; King and Waind, 1960), a view not universally accepted, because raised SLD levels are found in a variety of conditions (Agress and Estrin, 1963). Latterly the specificity of the SLD estimation has been improved by making use of the different characteristics of lactic dehydrogenase of heart muscle origin, compared to that of other tissues. Thus, lactic dehydrogenase from heart muscle will respond differently to the effect of heat (Wróblewski and Gregory, 1961), to acetone precipitation (Latner and Turner, 1963), to chloroform inhibition (Warburton and Smith, 1963), in substrate specificity (Elliot and Wilkinson, 1961), and in electrophoretic mobility (Wróblewski, Gregory, and Ross, 1960a; Van der Helm et al., 1962). Since all these characteristics have been used to devise more specific tests for myocardial infarction, it is apparent that it is this lack of specificity that has caused most concern in accepting enzymological findings when confirming a diagnosis of myocardial infarction.

It has recently been shown that estimation of serum creatine phosphokinase (SCPK) may provide a very specific test for heart muscle necrosis (Dreyfus et al., 1960; Smith, 1964). This enzyme exhibits maximum activity in striated muscle, brain, and heart muscle, and is known to be liberated into the blood stream within a very short time following myocardial infarction, and subsequent heart muscle necrosis. It achieves a peak of maximum activity 18-30 hours from onset, and returns to normal after 3-4 days total increase. Since the involvement of brain and skeletal muscle produces symptoms so clinically different from myocardial infarction it appears that estimation of SCPK would prove an ideal test, providing it could be carried out on specimens collected within 3 days of onset.

\section{Methods OF INVESTIGATION AND RESUltS}

To evaluate the usefulness of SCPK estimations, we carried out a series of tests comparing it with certain other enzyme tests used in the diagnosis of myocardial infarction. The tests were carried out on 20 patients who had recently suffered a myocardial infarction, on 10 patients who presented with symptoms which might be confused with myocardial infarction and required further investigation, and on 20 normal subjects. 
As comparative tests, we selected SGOT, SLD, serum $\alpha$-hydroxybutyrate dehydrogenase (SHBD), and electrophoretic separation with subsequent staining for lactic dehydrogenase (LD) activity. SHBD is a test that makes use of the greater affinity of heart SLD for a special substrate, in this case $\alpha$-hydroxybutyrate. Since the tests are somewhat specialized and open to various interpretations, we have listed these and the methods employed separately in the Appendix.

To establish the typical SCPK pattern of myocardial infarction, we were able to select 20 patients in whom we felt the diagnosis was not in doubt. Chest pain had been a prominent feature in every instance, with radiation of the pain to one or both arms occurring in 18 of the 20 patients. Ten gave a previous history of angina of effort, and 4 were clinically shocked on admission. In only one was there evidence of arrhythmia, this being in the form of multiple extrasystoles. Two of the male patients died; post-mortem findings indicated that one had died as a direct result of myocardial infarction and the other from cerebral embolus, secondary to a mural thrombus. All showed conclusive electrocardiographic evidence of acute infarction in the form of convex S-T segment elevation and deep symmetrical $T$ wave inversion, followed by the development of Q-S complexes or abnormal $Q$ waves (i.e. of $0.04 \mathrm{sec}$. or more in width). Eleven patients had anterior and 9 had posterior myocardial infarctions. When the serum of all 20 patients was examined electrophoretically for SLD isoenzymes, prominent $\mathrm{LD}_{5}$ and $\mathrm{LD}_{4}$ bands (heart LD) were present in every instance.

Figure 1 shows typical findings from one of these patients, although in this particular instance the SCPK remained raised for about $4 \frac{1}{2}$ days, which was the longest period of increase we recorded. Fig. 2 shows the total SCPK findings over the first few days, and in the proven myocardial infarctions the SCPK was raised to between 6 and 20 times the upper normal level, and remained raised up to $4 \frac{1}{2}$ days from infarction: the period of increase lasting for $4 \frac{1}{2}$ days was unusual, most having returned to normal after 3 days. One worker (Smith, 1964) reported that all serum levels were back to normal after 3 days, and another (Dreyfus et al., 1960) reported that the return to normal coincided very closely with that of the SGOT.

We were only able to collect 10 patients with clinical features simulating myocardial infarction

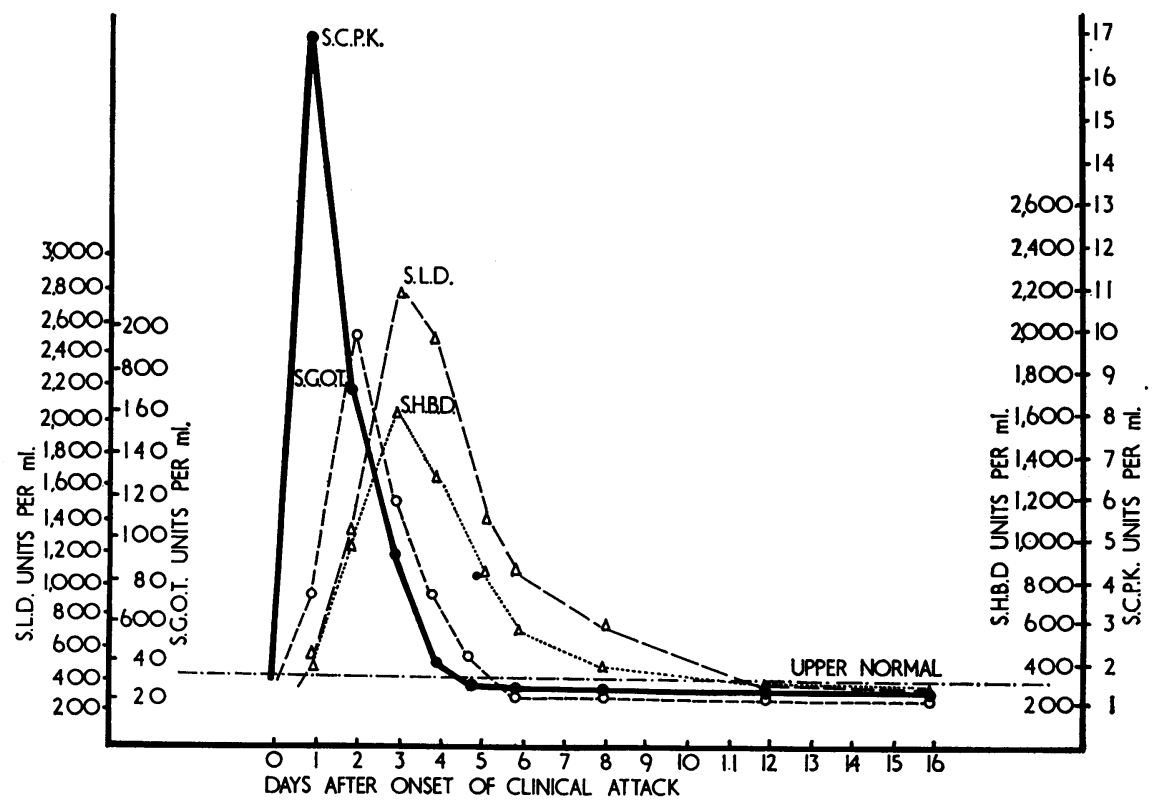

FIG. 1.-Serum enzyme levels following myocardial infarction showing the typical rise and fall of the four enzymes studied: SGOT, SLD, SHBD, and SCPK. 


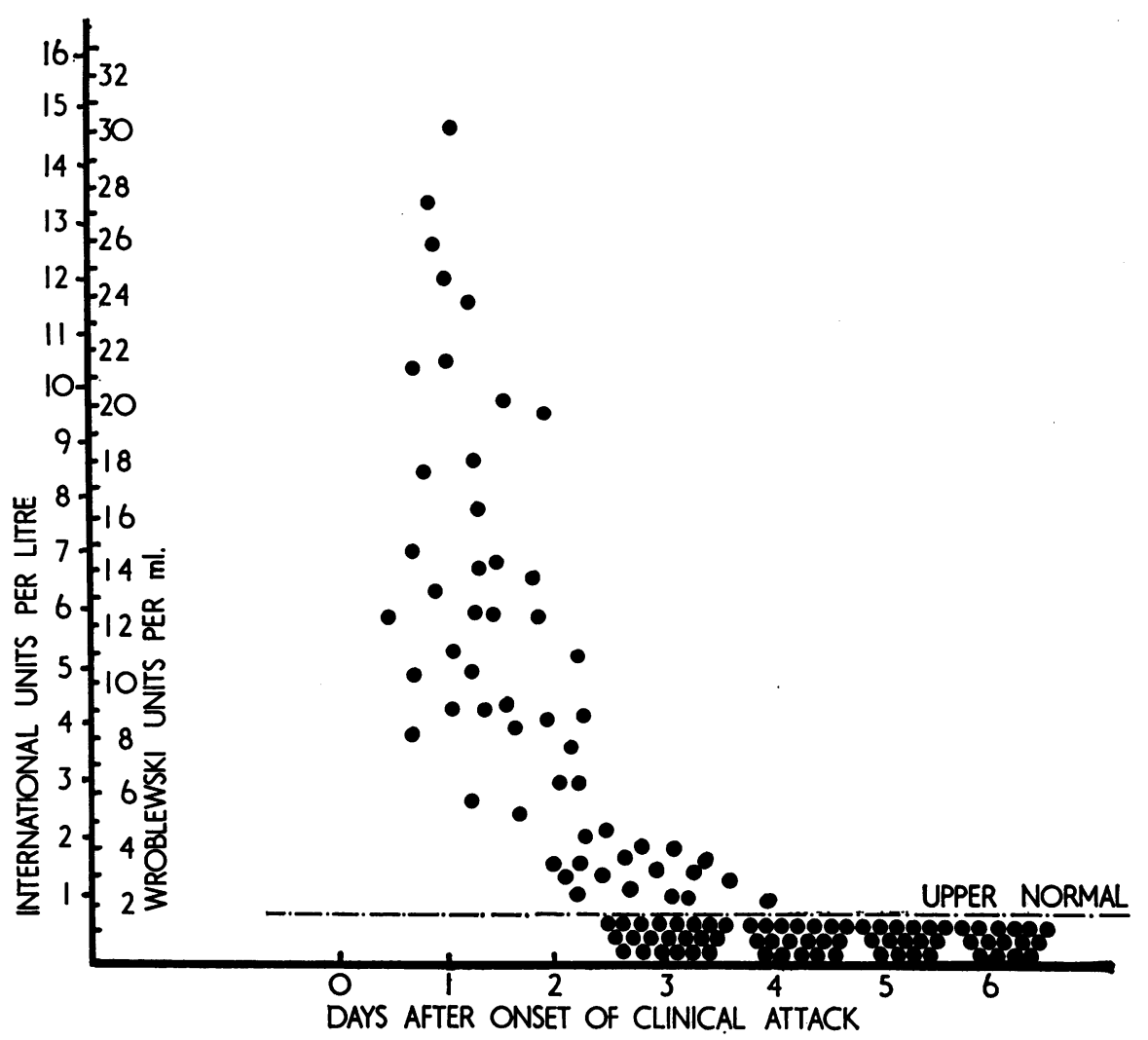

Fig. 2.-Collective results of the SCPK determinations carried out on the 20 patients with myocardial infarction.

on admission to hospital. These included patients with peptic ulceration, hiatus hernia, pulmonary infarction, pain of spinal origin, and atypical chest pain with equivocal electrocardiographic findings. In one or two patients slight increases of SGOT and SLD occurred, most probably caused by prolonged shock (Wilkinson, 1962). These patients are shown more fully in Group 2 in the Table, and though serial enzyme estimations were carried out on them, a raised SCPK was never demonstrated, and at no time were bands of heart LD detected by isoenzyme electrophoresis.

None of the normal subjects investigated showed a raised SCPK. Other enzyme levels were also normal in these subjects, apart from two SLD levels in the 500-550 region. These findings were in accordance with those of our previous investigation (Stewart and Warburton, 1961), and it does seem that normal SLD levels rarely exceed 400 Wróblewski units per ml. by the Sigma colorimetric method, but because of the peculiar function of the enzyme and its intimate connexion with the anærobic pathway, values of 400-500 Wróblewski units occur without any cellular necrosis being involved. Athletes for instance tend to maintain higher levels of SLD than other people (Halonen and Konttinen, 1962).

In this respect it is worthy of note that SCPK also tends to be slightly raised after exertion and even after moderate exercise.

One possibility we failed to investigate due to lack of patients, was the behaviour of SCPK in relation to the delayed rise in enzyme activity which occasionally occurs when marked hypotension is present immediately after infarction (Wright and Warburton, 1963). A feature very favourable to SCPK determination is its freedom from interference due to hæmolysis. So far as we were able to tell, hæmolysis had virtually no effect on the determination. 
TABLE

\begin{tabular}{|c|c|c|c|c|}
\hline Group & $\begin{array}{c}\text { Number of } \\
\text { patients }\end{array}$ & Diagnosis & SCPK & Other enzymes \\
\hline 1 & 20 & Myocardial infarction & $\begin{array}{l}\text { All } 20 \text { patients showed } \\
\text { typical rise and fall (Fig. } \\
\text { 1) over first } 4 \text { days }\end{array}$ & $\begin{array}{l}\text { Typical rise and fall of SGOT, } \\
\text { SLD, and SHBD (Fig. 1) } \\
\text { demonstrated in all } 20 \text { patients }\end{array}$ \\
\hline \multirow[t]{4}{*}{2} & 10 & Hiatus hernia (1) & Normal throughout & Normal throughout \\
\hline & & Nerve root pain (1) & Normal throughout & Normal throughout \\
\hline & & Peptic ulcer (4) & Normal throughout & $\begin{array}{l}3 \text { patients showed transient rise of } \\
\text { SGOT and SLD with normal } \\
\text { SHBD.; 1 patient with normal } \\
\text { SGOT, SLD, and SHBD levels } \\
\text { throughout }\end{array}$ \\
\hline & & Pulmonary embolus (4) & Normal throughout & $\begin{array}{l}2 \text { patients showed transient rise of } \\
\text { SGOT, SLD, and normal } \\
\text { SHBD; } 2 \text { patients with normal } \\
\text { SGOT, SLD, SHBD levels } \\
\text { throughout }\end{array}$ \\
\hline 3 & 20 & $\begin{array}{l}\text { Normal subjects (includ- } \\
\text { ing some staff) }\end{array}$ & $\begin{array}{l}\text { Normal (not examined } \\
\text { serially) }\end{array}$ & $\begin{array}{l}\text { SGOT, SHBD normal in every } \\
\text { instance; } 2 \text { SLDs in } 500-550 \\
\text { range; all other SLDs normal }\end{array}$ \\
\hline
\end{tabular}

Three further patients provided some interesting enzymological findings. One patient, who had been admitted to hospital, presented clinical evidence suggesting a diagnosis of mycocardial infarction. This was later confirmed by the presence of a typical electrocardiogram and raised levels of all the enzymes investigated, together with well-marked $\mathrm{LD}_{5}$ and $\mathrm{LD}_{4}$ (heart) bands on electrophoresis. All serum enzymes returned to almost normal levels except the SLD which was still raised 16 days after infarction (Fig. 3). In the course of further investigations this patient was found to have a megaloblastic anæmia, a condition in which the SLD remains high, the dual pathology offering a satisfactory explanation of the atypical increase in SLD from the point of view of his myocardial infarction.

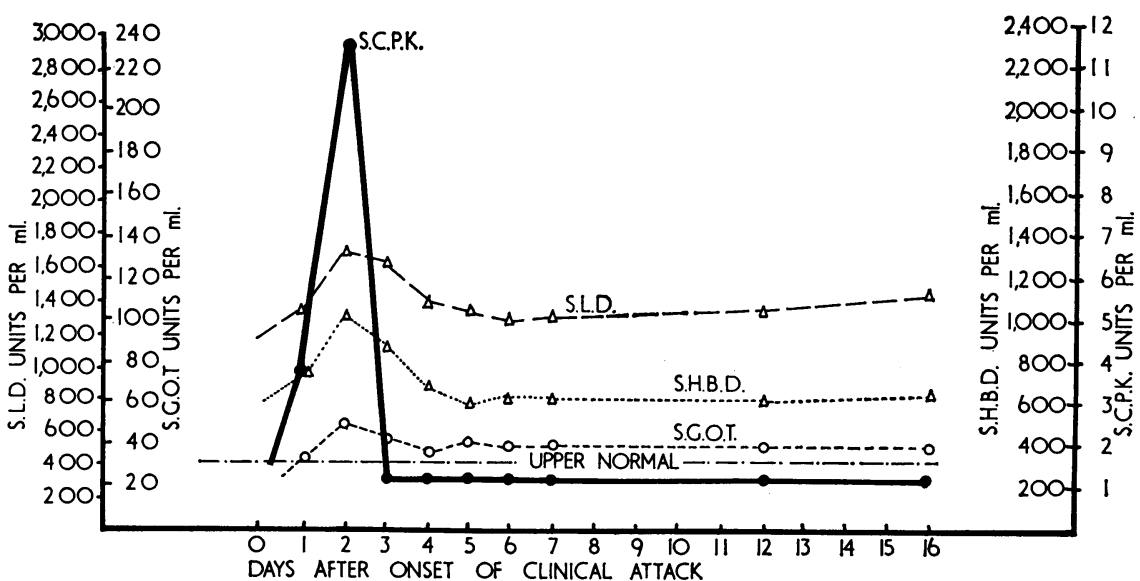

Fig. 3.-Myocardial infarction occurring in a patient who also had an untreated megaloblastic anæmia. 


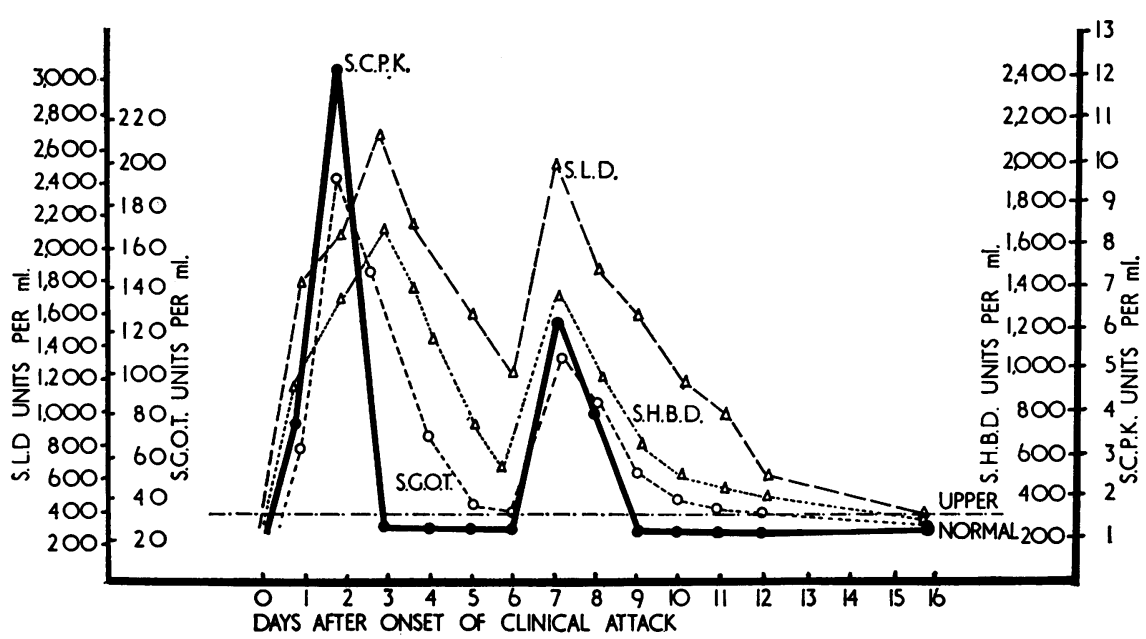

Fig. 4.-Serum enzyme levels in a patient who suffered a second myocardial infarction one week after the original infarction.

Two other patients with myocardial infarction suffered a further infarction during their stay in hospital. This was detectable by recurrence of chest pain and change in the electrocardiographic pattern. All enzymes showed a coincident rise, including a new increase in SCPK from the normal level to which it had returned. In neither instance was the new peak as high as the original one which followed the first infarction (Fig. 4).

\section{DisCUSSION}

From the results obtained, we concluded that in the first 48 hours, and possibly the first 72 hours from onset, a raised SCPK level is diagnostic of a myocardial infarction having occurred in a patient presenting with typical symptoms. In this respect it is superior to the SGOT and SLD determinations which show a certain lack of specificity and occasionally become raised in conditions of prolonged shock, probably due to a slight degree of liver cell necrosis.

Although in cases where enzyme levels are considerably raised, SHBD exhibits a good degree of specificity as an indication of heart muscle necrosis, it does not work too well at slightly raised levels, and in this respect SCPK is a superior test. We have found this criticism to be true of all the specialized tests for heart SLD mentioned in the introduction with the exception of the electrophoretic separation. Unfortunately, it is in cases where the slightly increased levels occur that the enzyme evidence is of most value, since these are usually the cases where electrocardiographic evidence is equivocal or lacking. We would, therefore, list the SCPK test and the electrophoretic determination of the isoenzyme pattern of LD isoenzymes, as the two most specific estimations for myocardial infarction.

For SCPK estimation, the blood specimen must be collected within at most 72 hours of onset, preferably within 48 hours. In the case of electrophoretic separation, the heart bands of $\mathrm{LD}_{5}$ and the lesser marked $\mathrm{LD}_{4}$ are reported to be still detectable two weeks after infarction (Latner and Skillen, 1961). This method is not particularly good for detecting second infarctions, rise in activity being judged by stain intensity, but the SCPK activity appears to be a very suitable test for this purpose.

With so many new and varying enzyme tests being added to the list of those useful in confirming a diagnosis of myocardial infarction, it becomes difficult for clinicians and laboratory workers to select those that are easiest to perform technically and at the same time to supply the most useful information. It seems that part of the evaluation of the usefulness of a test should be to indicate its place in the laboratory routine. 
It has been our view for some time that the greatest value can be derived from enzyme tests in diagnosing myocardial infarction only if there is utmost co-operation between clinicians and the laboratory. Probably the most useful method is to collect blood specimens daily on each of four days from onset, sending these immediately to the laboratory where the serum can be separated, checked for hæmolysis and stored.

If electrocardiographic findings are conclusive, and the physician is satisfied that a myocardial infarction has occurred, then no further laboratory investigations need be done, and the sera can be discarded, or saved for use as control sera to check subsequent tests.

However, in dubious cases, we would suggest SGOT and SLD determinations on all specimens, and SCPK determination on the first two or three, with recourse to electrophoresis for LD isoenzymes if necessary. We feel this would give ample coverage and enable any slight rise in SGOT to be assigned to the correct source. This means that we would preferably regard the SCPK as a confirmatory test, useful essentially because of its specificity. We have found estimation of SCPK at slightly raised levels to be rather critical and require careful checking and monitoring and for this reason prefer not to rely on it entirely in dubious cases.

\section{CONCLUSION}

Estimation of serum creatine phosphokinase (SCPK) appears to be a very specific test for myocardial infarction. It is comparable in specificity to electrophoresis of LD isoenzymes, superior to SHBD in the more critical range of slightly raised levels, and more specific than direct estimation of SGOT and SLD.

It can be performed on hæmolysed sera. The test must be carried out, however, on specimens collected very soon after onset, preferably within 48 hours, and certainly not later than 72 hours.

A somewhat large blood sample $(2 \mathrm{ml}$. of serum) is required and levels that are only slightly raised require careful checking. Because of this latter feature we prefer to regard it as a useful supplementary test, rather than an essentially diagnostic one. It also has a very useful function in detecting repeated myocardial infarctions occurring within a few days of the first episode, being superior to electrophoresis of LD isoenzymes in this respect.

\section{SUMMARY}

To assess the value of serum creatine phosphokinase (SCPK) estimations in the diagnosis of myocardial infarction, serial determinations of the serum enzyme activity were made over the first few days following infarction on 20 selected patients in whom the diagnosis had been firmly established. The SCPK levels increased from six to twenty times the normal value during the first 48 hours after onset, and had usually returned to normal after 72 hours; the maximum period of increase being one of $4 \frac{1}{2}$ days. Raised SCPK values were never demonstrated in a control series of 10 patients presenting with symptoms which might have been confused with those of myocardial infarction, or in 20 selected normal subjects.

Of four other enzyme tests run in parallel, only the electrophoresis of SLD isoenzymes produced a comparable standard of specificity. Slightly raised values of SGOT and SLD were sometimes found in conditions other than myocardial infarction, and though SHBD gave clear-cut results at high levels, we felt that slightly raised values were not specific.

Because of the brief period of increase, and the difficulty of estimation at slightly raised levels, we felt determination of SCPK activity would, at present, be more suitable as a confirmatory test rather than an essentially diagnostic one. It seems to be particularly useful for detecting repeat infarctions which occur soon after the first one, and for use on hæmolysed specimens, since hæmolysis does not give rise to raised values, although it may render the estimation more difficult.

\section{REFERENCES}

Agress, C. M., and Estrin, H. M. (1963). The Biochemical Diagnosis of Heart Disease, Part 1, p. 57. American Lecture Series, No. 548. Charles C. Thomas, Springfield, Illinois. 
Babson, A. L., Shapiro, P. O., Williams, P. A. R., and Phillips, G. E. (1962). The use of a diazonium salt for the determination of glutamic-oxalacetic transaminase in serum. Clin. chim. Acta, 7, 199.

Dreyfus, J. C., Schapira, G., Resnais, J., and Scebat, L. (1960). La créatine-kinase sérique dans le diagnostic de l'infarctus myocardique. Rev. franç Étud. clin. biol., 5, 386.

Elliot, B. A., and Wilkinson, J. H. (1961). " $\alpha$ hydroxybutyric dehydrogenase" in myocardial infarction and in liver disease. Lancet, 1, 698.

Halonen, P. I., and Konttinen, A. (1962). Effect of physical exercise on some enzymes in the serum. Nature (Lond.), $193,942$.

Karmen, A. (1955). A note on the spectrophotometric assay of glutamic-oxalacetic transaminase in human blood serum. J. clin. Invest., 34, 131.

King, J., and Waind, A. P. B. (1960). Lactic dehydrogenase activity in acute myocardial infarction. Brit. med. J., 2, 1361 .

LaDue, J. S., Wróblewski, F., and Karmen, A. (1954). Serum glutamic oxalacetic transaminase activity in human acute transmural myocardial infarction. Science, 120, 497.

Latner, A. L., and Skillen, A. W. (1961). Clinical applications of dehydrogenase isoenzymes. Lancet, $2,1286$. and Turner, D. M. (1963). Clinical application of the effect of acetone on serum lactate dehydrogenase. Lancet, $1,1293$.

Ressler, N., Joseph, R., and Schulz, J. (1962). Simple method for electrophoretic analysis of serum lactate dehydrogenase. J. Lab. clin. Med., 60, 349.

Rosalki, S. B., and Wilkinson, H. J. (1960). Reduction of $\alpha$ ketobutyrate by human serum. Nature (Lond.), 188, 1110.

Rowell, N. R., and Smith, A. J. (1959). Multiple serial enzyme studies in acute myocardial infarction. Brit. med.J., $2,459$.

Smith, A. F. (1964). Serum-enzymes in myocardial infarction. Lancet, 2, 1,143.

Stewart, T. W., and Warburton, F. G. (1961). Serum lactic dehydrogenase estimations in myocardial infarction. Brit. Heart J., 23, 236.

Van der Helm, H. J., Zondag, H. A., Hartog, H. A. Ph., and Van der Kooi, M. W. (1962). Lactic dehydrogenase isoenzymes in myocardial infarction. Clin. chim. Acta, 7, 540.

Warburton, F. G., and Smith, D. (1963). A simple method of differentiating between serum lactate dehydrogenase of cardiac origin and that derived from other tissues. Enzymologia, 26, 125.

Wilkinson, J. H. (1962). An Introduction to Diagnostic Enzymology, p. 125. Arnold, London.

Wróblewski, F., and Gregory, K. F. (1961). Lactic dehydrogenase isozymes and their distribution in normal tissues and plasma and in disease states. Ann. N..Y Acad. Sci., 94, 912.

, - and Ross, C. (1960a). Isozymes and myocardial infarction. Clin. Res., 8, 195.

, Ross, C., and Gregory, K. (1960b). Isoenzymes and myocardial infarction. New Engl.J. Med., $263,531$.

Wright, A. C., and Warburton, F. G. (1963). Determination of enzyme activity. Lancet, 2, 1285.

\section{APPENDIX \\ Methods Employed for Enzyme Estimation}

SGOT. Materials supplied by Dade were used for this estimation. This method uses the colour produced by the 2:4 dinitrophenylhydrazone and is claimed to be capable of reproducing results obtained by the ultraviolet reference method of Karmen (Karmen, 1955). However, it has been shown that this particular method tends to give rather lower results and that colour produced by coupling with certain diazo compounds will give results more in line with the Karmen method (Babson et al., 1962). We have found this to be so, and this may account for the suggested top normal level of 28-30 units for SGOT determined by the 2:4 dinitrophenylhydrazone method suggested by certain authors (Rowell and Smith, 1959; Stewart and Warburton, 1961). We retained the original colorimetric method for our investigations, as it is so universally employed.

$S L D$. Materials supplied by the Sigma Chemical Company were used. Normal range up to about 400 units per $\mathrm{ml}$., but as stated previously this may extend to 500 units per ml. under certain conditions.

$S H B D$. A kit of materials is provided by Dade, employing the colorimetric method of Rosalki (Rosalki and Wilkinson, 1960). These proved to be satisfactory but the method is rather time consuming due to the employment of a serum blank for each test, and a substrate and diphosphopyridine nucleotide blank required for each batch of tests. Top normal level is given as 300 units per $\mathrm{ml}$.

$S C P K$. Special kits of materials are supplied by C. F. Boehringer and Soehne, Germany. If made up according to instructions, they are reasonably stable. There is a certain variation in the stability of instruments used, and the change in absorbence for a normal SCPK level is only 0.005. We found the new Spectrochem instrument made by Hilger and Watts to be very suitable for this test. Because of this difficulty at low levels we aimed to control our tests with serum of known normal and raised CPK levels. The upper normal level is 1.5 Wróblewski units per $\mathrm{ml}$. or 0.7 international units per litre.

LD Isoenzyme Determination. This is not a particularly easy procedure; the difficulties fall into two categories: (1) obtaining a suitable electrophoretic separation, and (2) staining the strips to show enzyme 
activity. The first difficulty we overcame by using small strips of Cellogel (obtainable from Shandon Ltd.) on which separation occurs rapidly, distinctly, and very little current is required for separation. The staining method of Ressler (Ressler, Joseph, and Schulz, 1962) has been the most satisfactory in our experience and the bands of heart $\mathrm{LD}\left(\mathrm{LD}_{5}\right.$ and $\left.\mathrm{LD}_{4}\right)$ appear to be typical findings in myocardial infarction (Wróblewski, Ross, and Gregory, 1960b), migrating roughly to the $\alpha_{1}$ and $\alpha_{2}$ globulin position respectively.

The units of enzyme activity recommended by the manufacturers have been retained throughout. These are as follows:

Serum glutamic oxalacetic transaminase Sigma Frankel Units per ml.

Serum lactic dehydrogenase Berger-Broida Units per $\mathrm{ml}$.

Serum hydroxybutyrate dehydrogenase Conventional Units per $\mathrm{ml}$. Serum creatine phosphokinase Wróblewski Units per $\mathrm{ml}$. 